\title{
Preparation of PMMA/hBN Composite Coatings for Metal Surface Protection
}

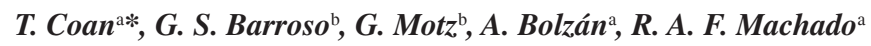 \\ ${ }^{a}$ Departamento de Engenharia Química e Engenharia de Alimentos, Federal University of Santa \\ Catarina - UFSC, Campus Universitário, Trindade, CP 476, CEP 88010-970, Florianópolis, SC, Brazil \\ ${ }^{\mathrm{b}}$ University of Bayreuth, Bayreuth, Germany - Lehrstuhl Keramische Werkstoffe, \\ Ludwig-Thoma-Str. 36b, 95447, Bayreuth, Bayern, Germany
}

Received: February 5, 2013; Revised: June 10, 2013

\begin{abstract}
Polyacrylics have been widely used in coatings. However, their application is limited by low corrosion resistance. One way to enhance their properties is the addition of fillers with adequate properties. In this study, composite materials of PMMA and hBN were developed and deposited on steel by dip-coating. The influence of the amount of $\mathrm{hBN}$ in the PMMA coating regarding corrosion resistance was investigated. The surface and cross-section of the coatings were characterized by SEM, the porosity was investigated by systematic manual point count and the adhesion was classified according to the tape test standard. The produced coatings were submersed in $\mathrm{NaCl}$ and $\mathrm{HCl}$ solutions to analyze corrosion resistance. The results showed that the PMMA/hBN composite coatings improved the corrosion resistance in comparison with pure PMMA. Additionally, the coatings are crack free and well bonded to the metallic substrate.
\end{abstract}

Keywords: Poly(methyl methacrylate), boron nitride, composite coatings, corrosion resistance, dip-coating

\section{Introduction}

Polyacrylics have increasingly been used as coatings, paints and adhesives due to their excellent performance of film-forming and good cohesiveness ${ }^{1,2}$, good weatherability, high strength, and excellent dimensional stability ${ }^{3}$. However, the low corrosion resistance limits their applications.

In order to improve corrosion resistance, the most commonly used strategy to reduce the release of ions is through surface modification methods, including surface passivation, electrochemical polishing, and polymerderived ceramic coatings ${ }^{4-6}$. However, for less aggressive environments, the application of such methods is not economically interesting. Therefore, the fabrication of polymeric coatings with protective performance and lower cost is an important technological improvement.

A suitable way to enhance the properties of the polymeric coatings is the addition of specific filler materials with the desired characteristic ${ }^{7}$. Boron nitride $(\mathrm{BN})$ is a material widely used in technological applications due to its unique chemical and physical properties, such as low density, high melting point, high thermal conductivity, good chemical resistance and inertness, low friction coefficient, high oxidation resistance, significantly high wear resistance and high electrical resistivity ${ }^{8,9}$. This ceramic is applied in bulk form and as thin films, fibers and coatings in electronic and ceramic composite applications ${ }^{10}$. BN has at least five known crystalline forms: cubic $(\mathrm{cBN})$, hexagonal $(\mathrm{hBN})$, wurtzite $(\mathrm{wBN})$, rhombohedral $(\mathrm{rBN})$ and rocksalt structure $^{11,12}$. For coating purposes, the lamellar structure of the hexagonal phase is the most interesting ${ }^{3}$, as it enables the

*e-mail: thaiscoan@gmail.com particles to align with the surface during coating application, improving the barrier properties ${ }^{13}$.

In this study, the method chosen to apply the coatings on the metal substrates is the dip-coating, which is an extensively used lacquer method. It stands out among available polymer coating methods like pulsed laser deposition (PLD) ${ }^{14}$ or thermal spraying ${ }^{15}$ due to its simplicity and low cost. In comparison with other simple and traditional polymer coating methods like spin-coating and spray-coating, dip-coating is more suitable for geometries like sheets, pipes and fibers, due to easy reproducibility of experimental conditions. In this processing, the solid substrates are simply immersed into a coating slurry, and withdrawn with controlled hoisting speed ${ }^{14-17}$. The main parameters in this coating process are the viscosity and density of the coating mixture, and the hoisting speed, which together determine the coating thickness ${ }^{18}$.

Zhi et al. ${ }^{19}$ manufactured composites of polystyrene and BN nanotubes (PS/BNNT) using a simple sonicationassisted solution-evaporation method. The tensile tests revealed that the elastic modulus increased up to $21 \%$ with just 1 wt. (\%) BNNT fraction. Furthermore, the composites showed a better resistance to oxidation than the pure polymer.

Zhi et al. ${ }^{20}$ fabricated poly(methyl methacrylate) and BNNT (PMMA/BNNT) composites and investigated their mechanical and thermal properties. The elastic modulus of PMMA was improved up to $19 \%$ using only a $1 \mathrm{wt}$. (\%) BNNT loading fraction. The PMMA/BNNT composite films simultaneously possessing (i) improved thermal conductivity, (ii) enhanced mechanical properties and 
(iii) perfect electrical insulation are expected to attend several applications in many polymeric fields.

Kiran et al. ${ }^{21}$ prepared PMMA/BN composites (containing 3 wt. (\%) of $\mathrm{BN}$ ) and studied the dependence of the mechanical properties on the number of BN particle layers. Experimental results showed that the hardness and elastic modulus of the PMMA/BN composite were higher in comparison with pure PMMA. Additionally, as the number of BN particle layers decreases, the effective surface area increases, enabling greater interactions between $\mathrm{BN}$ and PMMA. The authors concluded that this is the reason why the composite with the least number of $\mathrm{BN}$ layers has the highest stiffness and hardness.

Song et al. ${ }^{22}$ exfoliated hexagonal BN in organic medium and dispersed the resulting $\mathrm{BN}$ nanosheets in poly(vinyl alcohol) (PVA) and epoxy matrices. The results suggested that nanometric $\mathrm{BN}$ sheets provide films with superior thermal conductivity.

Madakbas et al. ${ }^{23}$ fabricated polyacrylonitrile (PAN)/ $\mathrm{hBN}$ composite coatings to investigate flame retardancy and thermal stability. The results showed that the limiting oxygen index (LOI) value of the composites increased up to $27 \%$ with the addition of $\mathrm{hBN}$. The glass transition temperature $(\mathrm{Tg})$ of PAN was found to be $83{ }^{\circ} \mathrm{C}$, and with $10 \% \mathrm{hBN}$ the $\mathrm{Tg}$ raised to $112{ }^{\circ} \mathrm{C}$. The authors attributed this behavior to the loss of mobility of the polymer chains due to the decrease in the free volume of the composites.

Although some studies in the field of PMMA/BN composites have been conducted, surprisingly the influence of the amount of $\mathrm{BN}$ in the PMMA coating regarding corrosion resistance has been neglected so far.

In the present study, composite materials of PMMA and $\mathrm{hBN}$ powder were developed, and the influence of the amount of $\mathrm{hBN}$ in the PMMA coating regarding corrosion resistance was evaluated. The composite coatings were deposited on AISI 304 stainless steel substrates. The surface and cross-section of the coatings were characterized by Scanning Electron Microscopy (SEM), the porosity was investigated by systematic manual point count (ASTM E 562-02) ${ }^{24}$ and the adhesion was investigated by tape test standard (ASTM D 3359) ${ }^{25}$. Additionally, the produced coatings were submersed in aqueous $\mathrm{NaCl}$ and $\mathrm{HCl}$ solutions to analyze corrosion resistance.

\section{Experimental}

\subsection{Materials}

The monomer methyl methacrylate (MMA), the initiator dicumyl peroxide (DCP) and the solvent toluene, were acquired from Sigma-Aldrich Corporation. Hexagonal boron nitride, used as passive filler, with a particle size $\mathrm{D}_{50}=0.7 \mu \mathrm{m}$ was obtained from Henze BNP GmbH. Disperbyk 2070, from BYK-Chemie GmbH, was used as an additive to disperse the ceramic powder. All the reagents were used as received, without further purification.

\subsection{Synthesis of PMMA}

Solution polymerization reactions were carried out in batch at $130{ }^{\circ} \mathrm{C}$ for 4 hours under pressure. In a typical procedure, $50.00 \mathrm{~g}$ toluene, $5.00 \mathrm{~g}$ MMA and $0.405 \mathrm{~g}$ DCP were added to $100-\mathrm{ml}$ stainless steel reactor equipped with a thermometer, argon inlet, and mechanical stirrer. After the polymerization reaction, toluene and residual monomer were removed from the mixture under reduced pressure for 4 hours. The average molecular weight of the purified PMMA, measured by gel permeation chromatography $(\mathrm{GPC})$, is $\mathrm{Mw}=320000 \mathrm{~g} / \mathrm{mol}(\mathrm{Mw} / \mathrm{Mn}=1.42)$.

\subsection{Preparation of $P M M A / B N$ composite coatings}

The hBN powder and the dispersant agent were added to toluene and treated in an ultrasound bath at $50{ }^{\circ} \mathrm{C}$ for 15 minutes, followed by a vigorous mechanical stirring for 24 hours. The formed stable suspension was used in subsequent procedures. The synthesized PMMA was dissolved in toluene under mechanical stirring for 5 hours, forming a $15 \mathrm{wt}$. (\%) solution. This solution was then mixed with different volumes of the hBN suspension. The sample codes and the resulting coating compositions after drying are given in Table 1.

\subsection{Substrate preparation and film deposition}

The AISI 304 stainless steel substrates were cut into $60 \times 30 \mathrm{~mm}$ sheets, sandblasted, cleaned in ultrasound bath with acetone and dried at room temperature. The dip-coating method (RDC 15 Relamatic, Glattburg, Switzerland) was used to apply the coatings to the steel sheets. In this procedure, the substrates were immersed in the coating slurry for 10 seconds and withdrawn with hoisting speed of $0.3 \mathrm{~m} / \mathrm{min}$ (Figure 1). Finally, the coated AISI 304 substrates were dried at $110^{\circ} \mathrm{C}$ in air for 12 hours.

Table 1. Specification of PMMA/hBN composite coatings.

\begin{tabular}{ccc}
\hline \multirow{2}{*}{ Sample Codes } & \multicolumn{2}{c}{ Composition } \\
\cline { 2 - 3 } & PMMA wt. (\%) & hBN wt. (\%) \\
\hline A & 100 & 0 \\
B & 90 & 10 \\
C & 70 & 30 \\
D & 50 & 50 \\
E & 30 & 70 \\
\hline
\end{tabular}

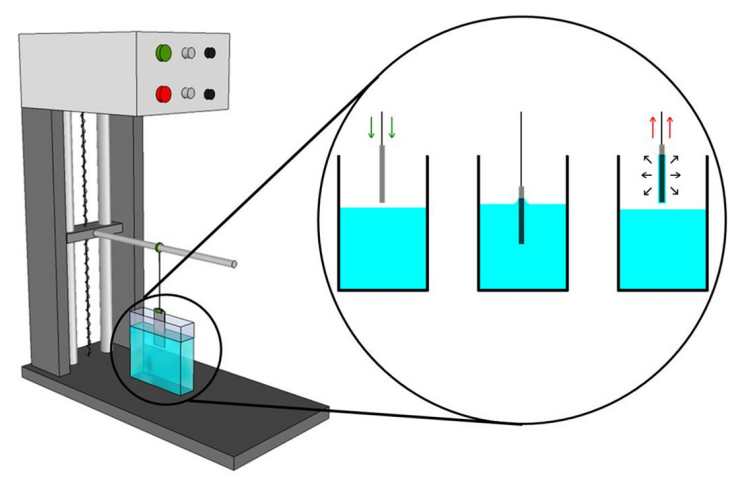

Figure 1. Schematic representation of dip-coating process. 


\subsection{Characterization}

The surface and cross-section of the coatings were analyzed by SEM (Jeol JSM-6400).

Porosity investigations were conducted according to ASTM E 562-02 24 , which statistically estimate the volume fraction of an identifiable constituent or phase from sections through the microstructure by means of a point grid superimposed over a SEM image. The method consists of systematic manual count of grid points falling within the constituent of interest, in this case, pores.

The adhesion of the pure PMMA and PMMA/hBN composite coatings on metallic substrate was investigated by tape test standard (ASTM D 3359) ${ }^{25}$, using an adhesion test kit (Gitterschnitt Geräte ZCC, from MTV Messtechnik $\mathrm{oHG}$ ). In this test, the surface of the samples was scratched to make grid lines of $1 \mathrm{~mm}$ squares. Then, an adhesive tape was applied and rapidly removed after 90 seconds in an angle as close to $180^{\circ}$ as possible. Following the described procedures, the samples were inspected by SEM to determine if any detachment of the coating has occurred.
In order to test the chemical barrier effect, the samples were immersed in $5 \mathrm{wt}$. (\%) $\mathrm{NaCl}$ aqueous solution at room temperature and removed for evaluation after 504 hours of exposure and visually inspected according to ASTM D $610^{26}$ (rusting degree). In addition, the samples were submersed in a $1 \mathrm{~N} \mathrm{HCl}$ solution, in order to investigate the anti-corrosive properties of the coatings in acidic environments. The weight loss of the samples was measured every hour until 5 hours of exposure and again after 15 hours. The results from this test are given according to the weight loss per area of coating $\left(\mathrm{mg} / \mathrm{mm}^{2}\right)^{8}$, enabling the comparison of the results with coatings on sheets of any dimension.

\section{Results and Discussion}

\subsection{Surface and cross-section SEM images}

Figure 2 shows SEM micrographs of the surface from each coating after drying at $110^{\circ} \mathrm{C}$ in air for 12 hours.

As can be observed in Figure 2, the coatings are considerably uniform and free of cracks. Another characteristic evidenced by SEM analysis is that the
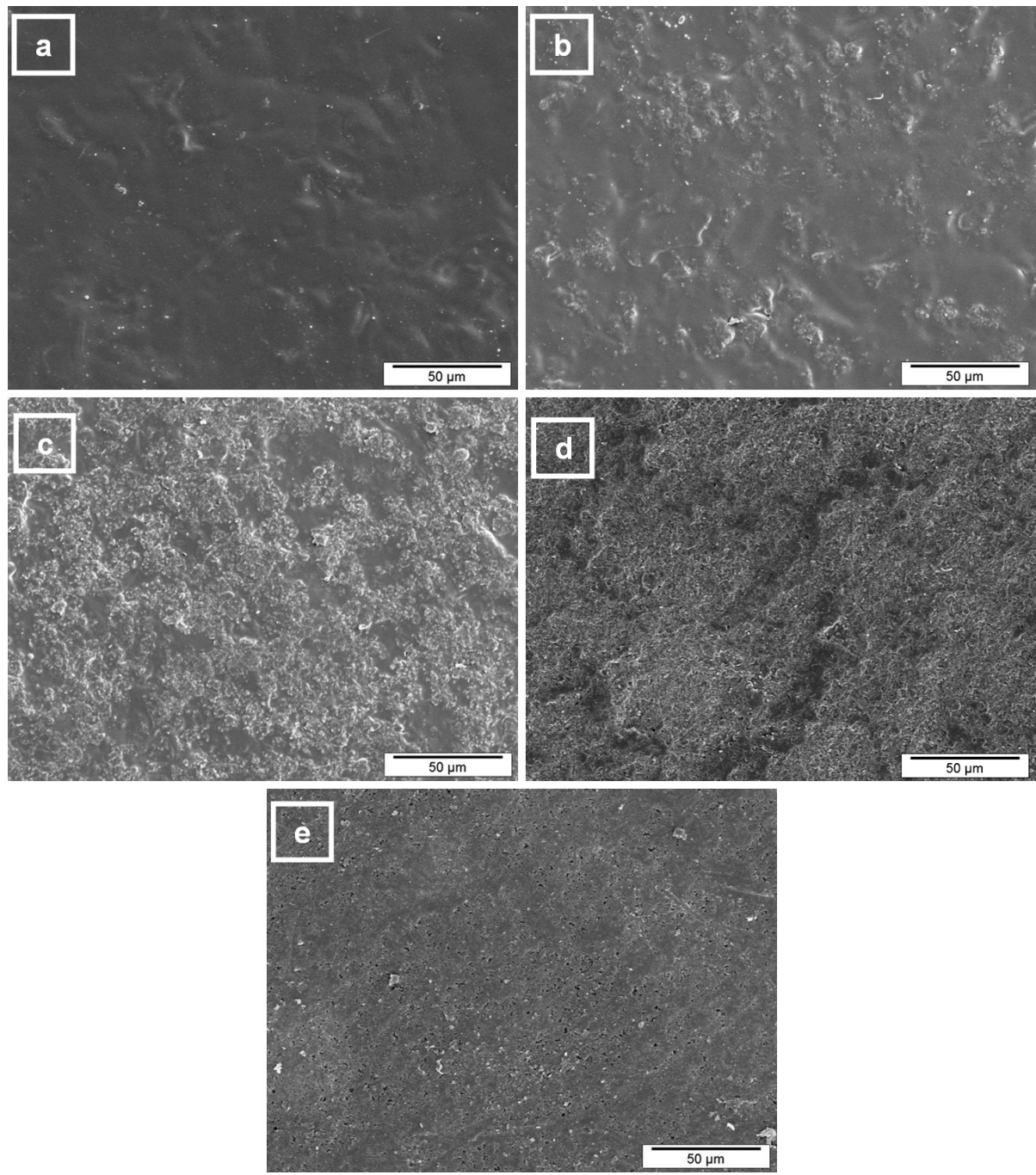

Figure 2. Micrographs of coatings from: (a) pure PMMA; (b) 90\%PMMA-10\%hBN; (c) 70\%PMMA-30\%hBN; (d) 50\%PMMA-50\%hBN; (e) 30\% PMMA-70\% hBN, on stainless steel. 
roughness of the surface increased considerably for hBN contents higher than 10 wt. (\%) (samples C, D, E). The porosity also changes with the $\mathrm{hBN}$ content (see section: 3.2). Besides, it can be seen that hBN was homogenously dispersed in the polymer matrix. Madakbas et al. ${ }^{23}$ reported similar results in PAN/hBN composite coatings. The surface

Cross-section SEM was conducted to evaluate the thickness of the coatings (Figure 3).

The average thickness of the samples A, B, C, D and E, respectively, are: $1.5 \mu \mathrm{m}, 1.5 \mu \mathrm{m}, 1.5 \mu \mathrm{m}, 2.0 \mu \mathrm{m}$ and $5.0 \mu \mathrm{m}$. It is important to emphasize that all the coatings were applied using the same hoisting speed and solutions concentration, which means that the increase in $\mathrm{hBN}$ content is responsible for the enhancement of the coatings thickness in samples D and E.

\subsection{Porosity of the coatings}

As mentioned earlier, the amount of $\mathrm{hBN}$ has influence on the porosity of the coatings. The porosity percentage estimated by analysis using the ASTM E562-02 24 is shown in Table 2. of the films became roughened with the addition of $\mathrm{hBN}$.

As described in Table 2, the porosity increases only slightly when the $\mathrm{hBN}$ concentration is increased up to 30 wt. (\%), i.e. samples B and C. However, further addition of hBN leads to a rapid increase of porosity, reaching $22 \%$ in sample D (50 wt. (\%) $\mathrm{hBN}$ ) and $43 \%$ in sample $\mathrm{E}$ (70 wt. (\%) hBN).

$\mathrm{Du}$ et al. ${ }^{27}$ observed similar pattern in $\mathrm{Ni}_{3} \mathrm{Al} / \mathrm{hBN}$ composite coatings. In their study, when the amounts of $\mathrm{hBN}$ added were $5 \mathrm{wt} .(\%)$ and $10 \mathrm{wt}$. (\%), the porosity increased to $14.17 \pm 1.01 \%$ and $17.92 \pm 1.42 \%$, respectively. When the hBN content reaches 15 wt. (\%), porosity increased dramatically to $28.31 \pm 1.88 \%$. For $\mathrm{Ni}_{3} \mathrm{Al}$ with 20 wt. (\%)

Table 2. Porosity of PMMA/hBN composite coatings.

\begin{tabular}{cc}
\hline Sample & Porosity (\%) \\
\hline A & 0 \\
B & 2.0 \\
C & 4.0 \\
D & 22.0 \\
E & 43.0 \\
\hline
\end{tabular}
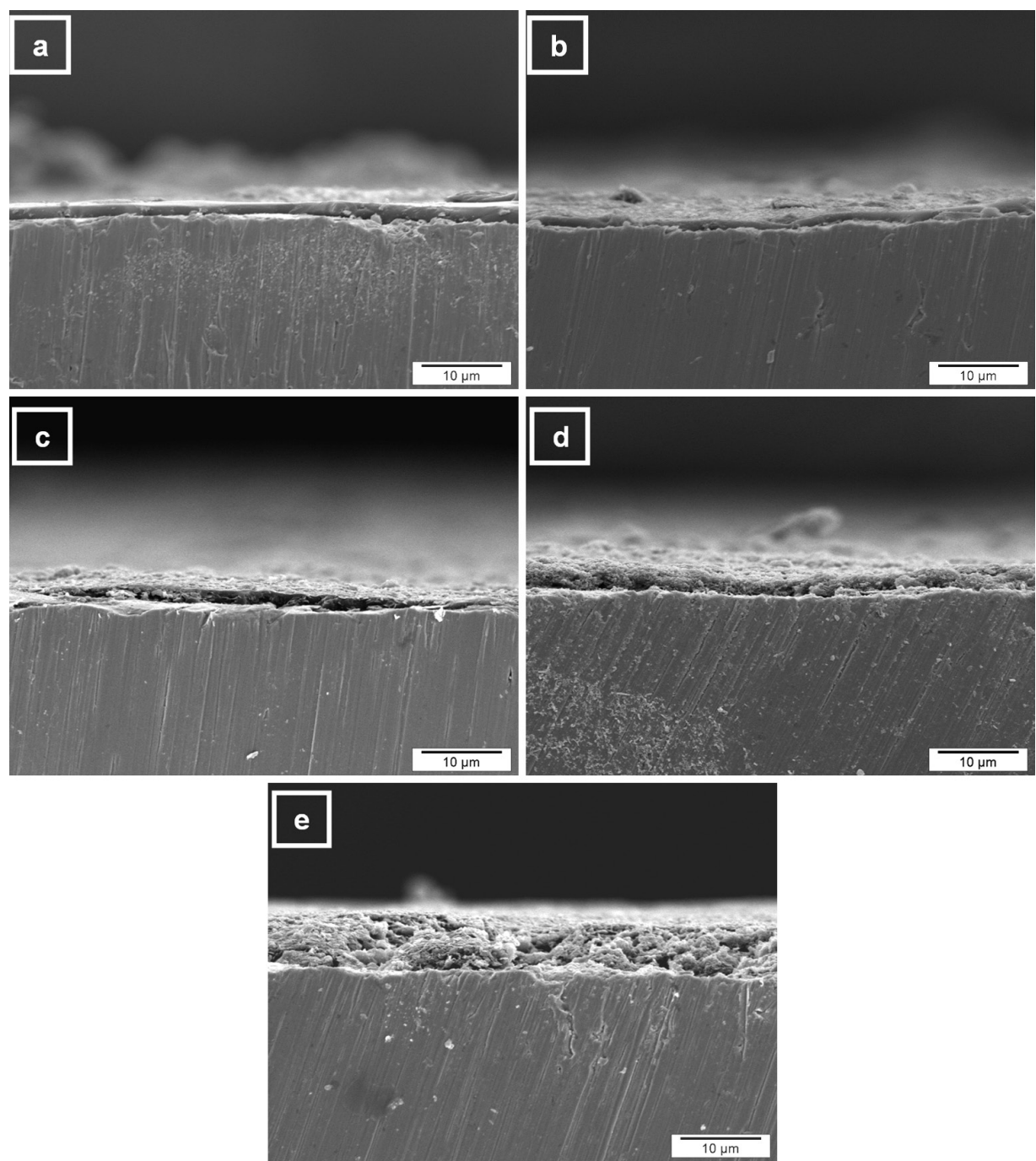

Figure 3. Micrographs of coatings from: (a) pure PMMA; (b) 90\%PMMA-10\%hBN; (c) 70\%PMMA-30\%hBN; (d) 50\%PMMA-50\% hBN; (e) $30 \%$ PMMA-70\% hBN, on stainless steel. 
$\mathrm{hBN}$, the porosity even exceeds $50 \%(53.38 \pm 2.57 \%)$. Thus, the results presented here are in agreement with this study, which concluded that addition of $\mathrm{hBN}$ in excess increases the porosity and destroys the continuity of the matrix, which is harmful to the tribological properties.

\subsection{Tape adhesion test (ASTM D 3359)}

The PMMA/hBN composite coatings on metallic substrate remained intact after the tape was stripped off. The same occurred with pure PMMA coating. The coatings were classified as $5 \mathrm{~B}$, which represents the best adhesion characteristic according to the standard ASTM $3359^{25}$. This classification means that the edges of the cuts are completely smooth and none of the squares of the lattice was detached as shown in Figure 4.

As showed, all the coatings are well bonded to the substrate (Figure 4). In the picture (e) from Figure 4, the scratches that are visible were caused during the experimental procedures. The amount of $\mathrm{hBN}$ in this sample has overcome the limit in which all the ceramic filler stays completely immersed in the polymer matrix after the evaporation of the solvent, creating a sample that is easily damaged by removing the excessive ceramic filler from the surface.

Besides, hBN has a lamellar crystalline structure, in which the bonding between molecules within each layer is strongly covalent, while the binding between layers is almost entirely by means of weak van der Waals forces, suggesting that the addition of $\mathrm{hBN}$ in excess might be prejudicial to the integrity of the coating ${ }^{27}$.

\subsection{Corrosion analysis}

It is known that polymeric coatings have been employed to protect metal against corrosion. Their primary effect is to create a physical barrier against aggressive species like $\mathrm{O}_{2}$ and $\mathrm{H}^{+}$. However, all polymeric coatings are not permanently impenetrable, and once there are defects in the coatings, pathways will be formed for the corrosive species to attack the metallic substrate and localized corrosion will occur ${ }^{3}$.

The results obtained after visual evaluation showed, after 504 hours of exposure to the $5 \mathrm{wt}$. (\%) $\mathrm{NaCl}$ solution, that only the samples $\mathrm{A}$ and $\mathrm{E}$ had signs of rusting, and were classified, respectively, as 9-P and 6-G, accordingly
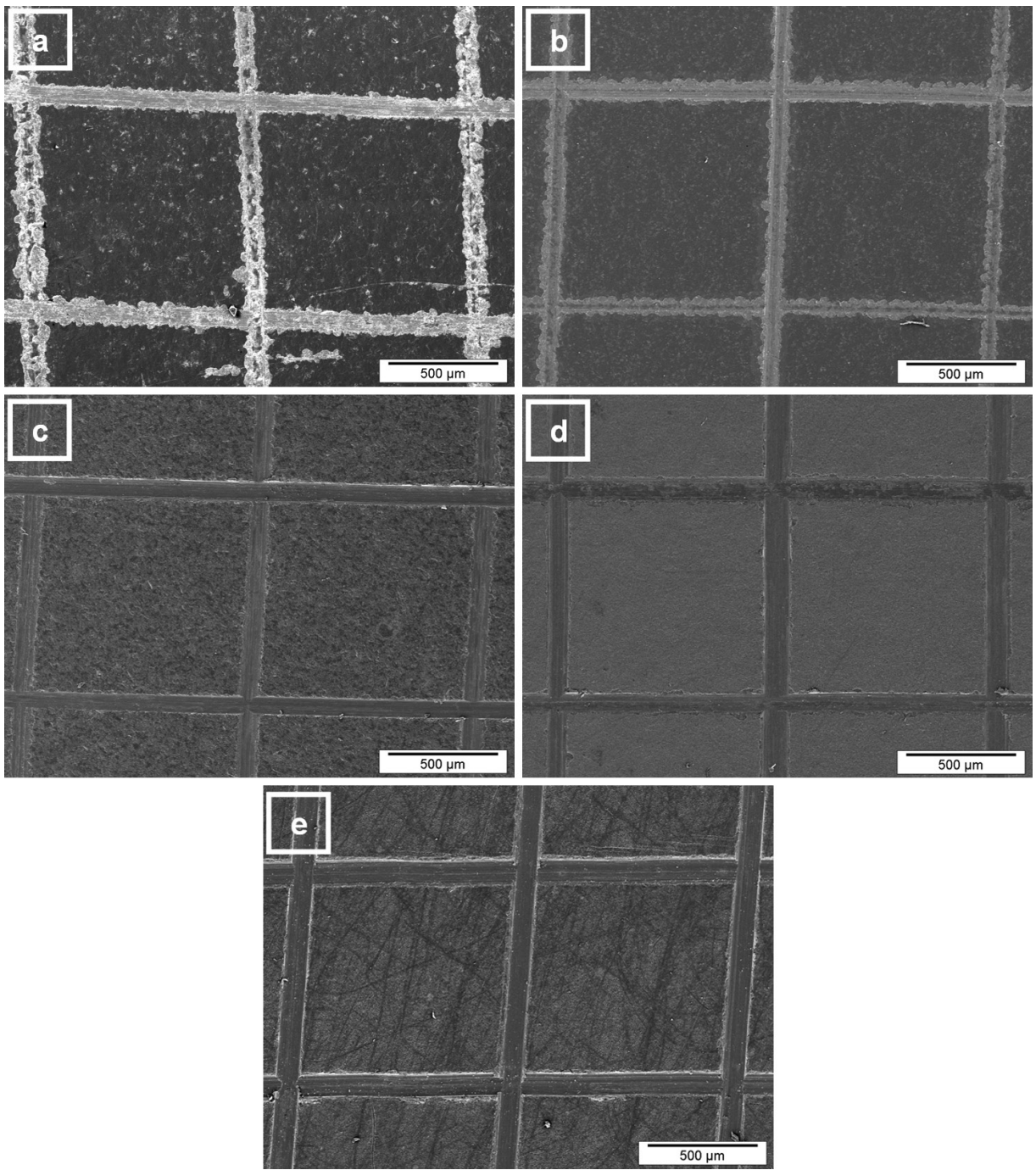

Figure 4. Micrographs of coatings from: (a) pure PMMA; (b) 90\%PMMA-10\%hBN; (c) 70\%PMMA-30\%hBN; (d) 50\%PMMA-50\%hBN; (e) $30 \%$ PMMA-70\% hBN, on stainless steel. 
to the ASTM D $610^{26}$. The rusting grade 9-P represents a pinpoint type rusting, with a rusted area greater than $0.01 \%$, up to $0.03 \%$ of the sample area. The grade $6-\mathrm{G}$ represents a general type rusting, in an area between $0.3 \%$ and $1.0 \%$ of the sample area. It is known that pure PMMA coatings have permeability to water and oxygen to a certain extent ${ }^{19}$, which favors the occurrence of corrosion. However, the high porosity of the composite coating from sample $\mathrm{E}$ has proven to be more prejudicial to the corrosion protection than the permeability of the pure PMMA coating. Corrosion resistance is strongly related to the porosity in the coating ${ }^{28}$, as it provides short-circuit paths for corrodants to penetrate through the coating.

On the other hand, the surface of the samples B, C and D remained apparently undamaged. This represents a rust grade of 10 (rusting in less than or equal to $0.01 \%$ of the surface). These results could be attributed to the good chemical resistance of $\mathrm{hBN}^{8,9}$ and enhancement of the barrier property due to the increase in the tortuosity of the diffusion pathways of oxygen and water ${ }^{29,30}$, which reduces the permeability of the coatings in comparison with pure PMMA ${ }^{3}$. However, all the coatings have provided some degree of corrosion protection, if compared to the uncoated substrate.

Figure 5 shows the weight loss of the coated samples as function of the submersion time in $1 \mathrm{~N} \mathrm{HCl}$ solution.

Although the sample A (pure PMMA) showed a good adhesion to the substrate, it is not resistant to corrosion by acid. The corrosion protection of the metallic substrates by simple organic layers as PMMA, is often low due to the poor acid resistance and to the permeability to water and oxygen $^{31}$. The total weight loss of this sample, after 15 hours, was $0.24 \mathrm{mg} / \mathrm{mm}^{2}$.

Despite the higher thickness, which is supposed to increase the barrier effect, sample E lost more weight $\left(0.28 \mathrm{mg} / \mathrm{mm}^{2}\right)$ than the other samples due to the higher porosity. As was described in the previous test with $\mathrm{NaCl}$ solution, porosity gives to the ions in solution a free path through the coating, increasing the extent of the acid attack to the polymeric matrix. After some time, the stress in the coating increases and cracks are formed due to the corrosion process started ${ }^{32}$, causing the collapse of the coating, and consequently, weight loss.

The best result was obtained with sample $\mathrm{C}$ where the total weight loss after 15 hours was $0.16 \mathrm{mg} / \mathrm{mm}^{2}$, which correspond to a decrease of $35 \%$ in comparison with pure PMMA. Thus, the degree of corrosion protection of the

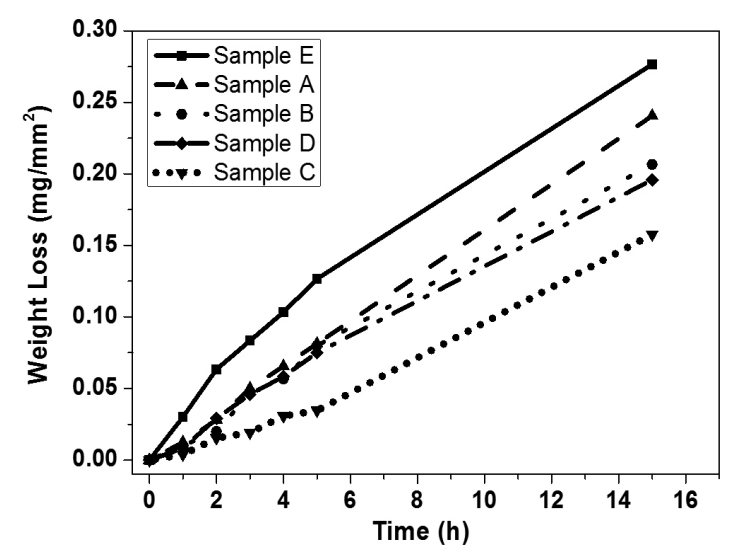

Figure 5. Weight loss of coated substrates as function of exposure time to $1 \mathrm{~N} \mathrm{HCl}$ solution. composite coatings seems to be a compromise between the amount of $\mathrm{hBN}$ in the coating and the consequent porosity. Although samples B and $\mathrm{C}$ had similar porosity ( $2.0 \%$ and $4.0 \%$, respectively), the performance of the sample $\mathrm{C}$ was better due to the higher amount of $\mathrm{hBN}$. However, even though samples D and $\mathrm{E}$ had higher amount of $\mathrm{hBN}$ in the coating, the porosity was also considerably higher than that of samples B and C $(22.0 \%$ and $43.0 \%$, respectively). Therefore, the inclusion of $\mathrm{hBN}$ in a PMMA matrix improves the resistance to acidic corrosion, due to good chemical resistance of $\mathrm{hBN}$ and to the reduction in permeability of $\mathrm{O}_{2}$ and $\mathrm{H}^{+}$(Figure 5), until a threshold valued is reached, over which the prejudicial effect of the porosity formed starts to overcome the beneficial aspects of the hBN.

When the hBN addition exceeds a critical value, the presence of porosity and the excessive amount of filler particles will destroy the continuity of the PMMA matrix. Moreover, the weak attraction forces between the hBN layers reduces the resistance of the coatings to the stresses caused by the corrosion, resulting in faster collapse. These may be the main reasons why the weight loss of the composite coatings increases dramatically when the $\mathrm{hBN}$ addition is higher than $30 \mathrm{wt}$. (\%).

\section{Conclusions}

In this work, composite materials of poly(methyl methacrylate) (PMMA) and ceramic hexagonal boron nitride $(\mathrm{hBN})$ powder were developed and deposited by dip-coating on AISI 304 stainless steel substrates. Different amounts of $\mathrm{hBN}$ in the PMMA coating were prepared in order to evaluate the protection of the metal surface regarding corrosion.

The SEM micrographs showed that the coatings applied with a hoisting speed of $0.3 \mathrm{~m} / \mathrm{min}$ were uniform, well bonded to the substrate and no segregation could be observed in all samples.

The porosity percentage, estimated according to ASTM E 562-02 24 , increased only slightly when the hBN content is increased up to $30 \mathrm{wt}$. (\%). However, further addition of $\mathrm{hBN}$ leads to a rapid increase of porosity, reaching $22 \%$ (50 wt. (\%) hBN) and $43 \%$ (70\% wt. (\%) hBN).

Additionally, the pure PMMA and PMMA/hBN composite coatings remained intact after the tape adhesion test and were classified as $5 \mathrm{~B}$, which represents the best adhesion characteristic according to the standard ASTM D $3359^{25}$.

After 504 hours of exposure to 5 wt. (\%) $\mathrm{NaCl}$ solution, the best anticorrosive properties were obtained with the samples B, C and D. The surface of these samples remained apparently undamaged, which according to ASTM D $610^{26}$ represents rusting in less than or equal to $0.01 \%$ of the surface. However, the sample $\mathrm{C}$ (ratio of 70:30 PMMA/hBN) gave the best anticorrosive performance after 15 hours immersed in a $1 \mathrm{~N} \mathrm{HCl}$ solution. This behavior can be explained by: (i) the higher content of $h B N$ powder, comparing to samples $\mathrm{A}$ and $\mathrm{B}$, which provided better acid resistance; (ii) the adequate porosity balance, comparing to samples $\mathrm{D}$ and $\mathrm{E}$, which prevents the penetration of $\mathrm{HCl}$ solution in the coating.

\section{Acknowledgements}

The authors would like to acknowledge CAPES (Coordenação de Aperfeiçoamento de Pessoal de Nível Superior - Brazil) and DAAD (Deutscher Akademischer Austauschdienst - Germany) for the financial support. 


\section{References}

1. Mingxuan Z, Fangzhi H, Jun N, Zhicheng Z and Xuewu G. Preparation and characterization of polysiloxanepolyacrylates composite latices and their film properties. Polymer International. 2005; 54:861-869. http://dx.doi. org/10.1002/pi.1759

2. Li B, Zhang S, Xu Q and Wang B. Preparation of composite polyacrylate latex particles with in situ-formed methylsilsesquioxane cores. Polymers for Advanced Technologies. 2009; 20:1190-1194. http://dx.doi.org/10.1002/ pat.1371

3. Yeh J, Liou S, Lin C, Cheng C and Chang Y. Anticorrosively Enhanced PMMA-Clay Nanocomposite Materials with Quaternary Alkylphosphonium Salt as an Intercalating Agent. Chemistry of Materials. 2002; 14:154-161. http://dx.doi. org/10.1021/cm010337f

4. Caselis JLV, Rosas ER and Meneses VMC. Hybrid PMMAsilica anticorrosive coatings for stainless steel 316L. Corrosion Engineering, Science and Technology. 2012; 47(2):131-137. http://dx.doi.org/10.1179/1743278211Y.0000000035

5. Günthner M, Kraus T, Dierdorf A, Decker D, Krenkel W and Motz G. Advanced coatings on the basis of $\mathrm{Si}(\mathrm{C}) \mathrm{N}$ precursors for protection of steel against oxidation. Journal of the European Ceramic Society. 2009; 29:2061-2068. http://dx.doi. org/10.1016/j.jeurceramsoc.2008.11.013

6. Günthner M, Schütz A, Glatzel U, Wang K, Bordia RK, Greiß1 $\mathrm{O}$ et al. High performance environmental barrier coatings, Part I: Passive filler loaded $\mathrm{SiCN}$ system for steel. Journal of the European Ceramic Society. 2011;31:3003-3010. http://dx.doi. org/10.1016/j.jeurceramsoc.2011.05.027

7. Xu X, Zhanga Z, Guoa F, Yanga J and Zhu X. Fabrication of superhydrophobic binary nanoparticles/PMMA composite coating with reversible switching of adhesion and anticorrosive property. Applied Surface Science. 2011; 257:7054-7060. http://dx.doi.org/10.1016/j.apsusc.2011.02.136

8. Günthner M, Kraus T, Krenkel W and Motz G. Particle-Filled PHPS Silazane-Based Coatings on Steel. International Journal of Applied Ceramic Technology. 2009; 6(3):373-380. http:// dx.doi.org/10.1111/j.1744-7402.2008.02346.x

9. Das M, Basu AK, Ghatak S and Joshi AG. Carbothermal synthesis of boron nitride coating on PAN carbon fiber. Journal of the European Ceramic Society. 2009; 29:2129-2134. http:// dx.doi.org/10.1016/j.jeurceramsoc.2008.12.004

10. Arya SPS and Amico AD. Preparation, properties and applications of boron nitride thin films. Thin Solid Films. 1988; 157:267-282. http://dx.doi.org/10.1016/00406090(88)90008-9

11. Mosuang TE and Lowther JE. Relative stability of cubic and different hexagonal forms of boron nitride. Journal of Physics and Chemistry of Solids. 2002; 63:363-368. http://dx.doi. org/10.1016/S0022-3697(00)00254-7

12. Joni IM, Balgisa R, Ogia T, Iwakia T and Okuyamaa K. Surface functionalization for dispersing and stabilizing hexagonal boron nitride nanoparticle by bead milling. Colloids and Surface A: Physicochemical and Engineering Aspects. 2011; 388:49-58. http://dx.doi.org/10.1016/j.colsurfa.2011.08.007

13. Cussler EL. Diffusion Barriers. Diffusion Fundamentals. 2007; 6:1-72.

14. Iqbal S, Rafique MS, Anjum S, Hayat A and Iqbal N. Impact of X-ray irradiation on PMMA thin films. Applied Surface Science. 2012; 259:853-860. http://dx.doi.org/10.1016/j. apsusc.2012.07.146

15. Zhang T, Gawne DT and Bao Y. The influence of process parameters on the degradation of thermally sprayed polymer coatings. Surface and Coatings Technology. 1997; 96:337-344. http://dx.doi.org/10.1016/S0257-8972(97)00269-7

16. Ruschak KJ. Coating Flows. Annual Review of Fluid Mechanics. 1985; 17:65-89. http://dx.doi.org/10.1146/annurev. fl.17.010185.000433

17. Snoeijer JH, Ziegler J, Andreotti B, Fermigier M and Eggers J. Thick Films of Viscous Fluid Coating a Plate Withdrawn from a Liquid Reservoir. Physical Review Letters. 2008; 100(244502):1-4.

18. Landau L and Levich B. Dragging of a liquid by a moving plate. Acta Physicochimica. 1942; 17:42-54.

19. Zhi CY, Bando Y, Wang WL and Tang CC. Boron nitride nanotubes/polystyrene composites. Journal of Materials Research. 2006; 21(11):2794-2800. http://dx.doi.org/10.1557/ jmr.2006.0340

20. Zhi CY, Bando Y, Wang WL, Tang CC, Kuwahara H and Golber D. Mechanical and Thermal Properties of Polymethyl Methacrylate-BN Nanotube Composites. Journal of Nanomaterials. 2008; 18:1-5. http://dx.doi. org/10.1155/2008/642036

21. Kiran MSRN, Raidongia K, Ramamurty U and Rao CNR. Improved mechanical properties of polymer nanocomposites incorporating graphene-like BN: Dependence on the number of BN layers. Scripta Materialia. 2011; 64:592-595. http:// dx.doi.org/10.1016/j.scriptamat.2010.12.007

22. Song W, Wang P, Cao L, Anderson A, Meziani MJ, Farr AJ and Sun Y. Polymer/Boron nitride nanocomposite materials for superior termal transport performance. Angewandte Chemie International. 2002; 51:1-5.

23. Madakbas S, Çakmakçi E and Kahraman MV. Preparation and thermal properties of polyacrylonitrile/hexagonal boron nitride composites. Thermochimica Acta. 2013; 552:1-4. http://dx.doi. org/10.1016/j.tca.2012.11.011

24. American Society for Testing and Materials - ASTM. E 562-02: Standard Test Method for Determining Volume Fraction by Systematic Manual Point Count. ASTM; 2002.

25. American Society for Testing and Materials - ASTM. D 3359: Measuring Adhesion by Tape Test. ASTM; 2002.

26. American Society for Testing and Materials - ASTM. D 610: Evaluating Degree of Rusting on Painted Steel Surfaces. ASTM; 2008.

27. Du L, Zhang W, Liu W and Zhang J. Preparation and characterization of plasma sprayed Ni3Al-hBN composite coating. Surface and Coatings Technology. 2010; 205:24192424. http://dx.doi.org/10.1016/j.surfcoat.2010.09.036

28. Riedel W. Electroless Nickel Plating. Stevenage: Finishing Publications Ltd; 1991.

29. Yeh J, Liou S, Lai M, Chang Y, Huang C, Chen C et al. Comparative studies of the properties of poly(methyl methacrylate)-clay nanocomposite materials prepared by in situ emulsion polymerization and solution dispersion. Journal of Applied Polymer Science. 2004; 94:1936-1946. http://dx.doi. org/10.1002/app.21095

30. Chang K, Chen S, Lin H, Lin C, Huang H, Yeh J et al. Effect of clay on the corrosion protection efficiency of PMMA/Na+-MMT clay nanocomposite coatings evaluated by electrochemical measurements. European Polymer Journal. 2008; 44:13-23. http://dx.doi.org/10.1016/j. eurpolymj.2007.10.011

31. Jones DA. Principles and prevention of corrosion. 2nd ed. 1996.

32. Rocha AC, Rizzo F, Zeng C and Paes MP. Duplex Albased thermal spray coatings for corrosion protection in high temperature refinery applications. Materials Research. 2004; 7:189-194. http://dx.doi.org/10.1590/S151614392004000100025 